\title{
Does Emotional Resilience Enhance Foster Placement Stability? A Qualitative Investigation
}

\author{
Sally Preston ${ }^{1}$, Kevin Yates ${ }^{2} \&$ Mark Moss ${ }^{3}$ \\ ${ }^{1}$ Academic Psychiatry, Newcastle University, UK \\ ${ }^{2}$ Children and Young People's Service, Monkwearmouth Hospital, Sunderland, UK \\ ${ }^{3}$ Department of Psychology, Northumbria University, UK \\ Correspondence: Sally Preston, Academic Psychiatry, Wolfson Research Centre, Campus for Ageing and Vitality, \\ Newcastle Upon Tyne, NE4 5PL, UK. Tel: 44-191-208-1373. E-mail:sally.preston@ncl.ac.uk
}

\author{
Received: May 18, 2012 Accepted: August 3, $2012 \quad$ Online Published: August 27, 2012 \\ doi:10.5539/ijps.v4n3p153 URL: http://dx.doi.org/10.5539/ijps.v4n3p153
}

\begin{abstract}
Frequent changes of foster placement are known to have a detrimental effect on the long-term well-being of cared-for children. Foster carers who take on children with challenging behaviours have to draw on resources, both internal and external, to help them build and maintain a relationship with the child that will last. Not all foster carers are successful in this regard. The aim of this qualitative study was to explore the role that the emotional resilience of foster carers plays in promoting placement stability.

Seven foster carers, who had a track-record of stable placements (according to national criteria) with children exhibiting challenging behaviours, were recruited from a Local Authority in the North East of England. They attended a focus group and one-to-one interview. Verbatim transcripts were subjected to an inductive grounded theory analysis.

Three potential underlying constructs, namely emotional resilience, interpersonal characteristics and external factors, were found to emerge from the data and identified as likely to influence foster placement outcomes. These data provide a springboard for further quantitative investigation with the potential to screen prospective carers to identify those best suited to "difficult" placements in order to maximise success for the benefit of all concerned.
\end{abstract}

Keywords: emotional resilience, foster carers, placement stability

\section{Introduction}

Large numbers of children in England are looked after by foster carers, with the majority of children entering the care system as a result of abuse and neglect ("Children looked after in England (including adoption and care leavers) year ending 31 March 2010,” 2010). Many children in care have emotional and behavioural difficulties and present with challenging behaviours; resulting in frequent moves between care placements. A number of factors contribute to placement stability, but of these, the role of the foster carer is of interest here. Why do some foster carers cope in the face of difficult, challenging behaviours whereas others do not?

One possibility is that foster carers draw on emotional resilience in order to maintain the fostering relationship in the face of challenging behaviours exhibited by the child. The research literature identifies two theoretical constructs in this domain. Ego-resiliency is conceptualised as a personality trait which is employed to regulate ego-control, the expression or inhibition of impulse. Resilient individuals are able to modulate their level of ego-control according to the situation, thus resulting in positive adaptation (Funder, Block, \& Block, 1983; Letzring, Block, \& Funder, 2005). An alternative construct is resilience; a concept attributed to individuals who, in the face of adverse, stressful situations, have positive psychological outcomes (Rutter, 2006). This model of resilience is rooted in adverse childhood experiences that lead to the development of dynamic psychological processes and positive adaptation (Werner, 1993). As such it is conceived as being different to ego-resiliency (Luthar, Cicchetti, \& Becker, 2000). However, Block and Kremen (1996) assert that resilience can be entirely accommodated within ego-resiliency. In the study reported here, there was no pre-conception of "emotional resilience" being wholly attributable to either ego-resiliency or resilience. 
Placement stability is used as a measure of successful foster placements; nationally it is defined by the number and duration of placements: fewer than three placements in a year (1 April to 31 March) and a placement duration of two years for foster children who were in care for at least $2 \frac{1}{2}$ years ("National Indicators for Local Authorities and Local Authority Partnerships: Updated National Indicator Definitions," 2009). In the year to March 2010, nationally $10.9 \%$ of foster children had been in three or more placements and $32 \%$ who had been in care for $2 \frac{1}{2}$ years had been in a placement lasting less than two years ("Children looked after in England (including adoption and care leavers) year ending 31 March 2010," 2010). However, research studies indicate that placement instability is a bigger problem than these national statistics suggest. Farmer, Lipscombe, and Moyers (2005) reported that $44 \%$ of placements failed within the first year and $53 \%$ of placements were under "severe difficulty" after one year. Similarly, Ward (2009) found that only $19 \%$ of children in her study stayed in the same placement for $3 \frac{1}{2}$ years compared to $22 \%$ who had had more than five placements. The length of placements tended to be short with only $29 \%$ lasting longer than a year and $21 \%$ of placement moves occurring as a result of a foster carer request.

Attachment of a child to their primary caregiver provides the child with a secure base from which to explore the world (Ainsworth, 1979). Foster children entering the care system may have been subjected to neglect, abuse and trauma. It is known that children who have been maltreated are more likely to exhibit insecure or disorganised attachment caused by the conflict (for the child) between the parent as the source of both security and fear (Cyr, Euser, Bakermans-Kranenburg, \& Van Ijzendoorn, 2010). Insecurely attached children tend to exhibit both internalising and externalising behaviours such as being withdrawn (internalising) or aggression (externalising) making the formation of close, stable relationships difficult. Additionally, maltreated children have been shown to have low resilient functioning compared to non-maltreated children (Flores, Cicchetti, \& Rogosch, 2005) and children who do poorly in their foster placements often exhibit maladaptive behaviours associated with poor resilient functioning (Schofield \& Beek, 2005b). Flores et al. (2005) also reported that maltreated children find it difficult to form positive relationships with adults outside their immediate family. This may be an important factor in the establishment of close, stable relationships with foster carers, and being able to benefit from the support on offer from outside agencies (school, for example).

Placement instability has been implicated in poor psychological outcomes such as mental health problems (Minnis \& Devine, 2001) and conduct disorders (Leathers, 2002). Furthermore, foster children are known to have low self-esteem which can be influenced by their foster carers for better or worse (Luke \& Coyne, 2008). In a study of Looked After Children, approximately half of the children had emotional and behavioural difficulties with $65 \%$ of boys in foster care exhibiting problems compared to $36 \%$ of girls (Minnis \& Del Priori, 2001). Many of these difficulties were attributable to attachment disorders. In England, 39.9\% of children in Local Authority foster placements have been shown to have a mental disorder, with $33.3 \%$ having a conduct disorder, $8.7 \%$ an emotional disorder (anxiety, depression) and $8.0 \%$ a hyperkinetic disorder (Meltzer, Gatward, Corbin, Goodman, \& Ford, 2003). The same report highlighted that other behaviours, known to have negative outcomes for health and well-being, such as smoking and drinking alcohol, decrease in prevalence as time in foster placement increases.

A number of factors have been identified to negatively impact on placement stability; increasing age of the child, gender (male), behaviour problems and previous placement history (Oosterman, Schuengel, Slot, Bullens, \& Doreleijers, 2007; Webster, Barth, \& Needell, 2000). The problem is circular however. Both externalising and internalising behaviours have been shown to be exacerbated by placement instability, with externalising behaviours strongly predictive of placement breakdown, and internalising behaviours increasing with the number of placements (Newton, Litrownik, \& Landsverk, 2000). Such associations between placement instability and behavioural problems have been widely reported elsewhere, (for example, Palmer, 1996; Rubin, O'Reilly, Luan, \& Localio, 2007).

Whilst the characteristics of the foster child are clearly important in placement stability, it is also influenced by the quality of relationships formed between the foster child and a number of significant others, primarily the foster carer. Sinclair and Wilson (2003) investigated the foster carer/child relationship, in particular the significance of the child characteristics, foster carer characteristics and interactions between the child and foster carer on placement success. In addition to the child's motivation for a particular placement, foster carers with appropriate parenting skills, who were "warm", encouraging and resilient, made a positive contribution to placement success. Interaction between the child and carer was also important, particularly how much the carer liked or rejected the child. Schofield and Beek (2005b) reported that children in foster care who made good progress had foster carers who were able to provide a secure base from which the child could be more adaptive and form relationships outside the family. These children and carers had close relationships; the foster carers 
exhibited resilience and had good supportive networks. Foster carers who were highly sensitive were more likely to form these close, stable relationships (Schofield \& Beek, 2005a). These researchers defined foster carer sensitivity across five dimensions related to their ability to promote in the child: trust in the foster carer's availability; an ability to reflect on thoughts and feelings; self-esteem; the ability to make their own decisions; and a feeling of belonging in the foster family.

A review of research on predictors of positive outcomes for foster care (Redding, Fried, \& Britner, 2000) identified the importance of foster carer personality characteristics, such as a balance between extraversion and introversion and using the traits of thinking and feeling in decision making. In the face of challenging behaviour, the ability of the foster carer to cope with their feelings of distress (sadness, disappointment and frustration, for example) could be an important factor in placement stability. This distress tolerance has four aspects: the person's subjective appraisal of the degree of distress; their perception of their ability to tolerate emotional distress; the extent to which they become absorbed by the emotional distress; and their ability to regulate the distressing emotions such that they can function normally (Simons \& Gaher, 2005). The ability to persevere in the face of challenging behaviour that causes emotional distress may be associated with motivation. A study carried out in the UK which examined the motivation of women to foster found that having a strong personal desire to foster, adverse childhood experiences or a sense of social responsibility were all related to being rated as an excellent foster carer and placements that lasted at least one year (Dando \& Minty, 1987).

Interestingly, foster carers who were able to manage challenging behaviour were more likely to report feelings of well-being, to gain personal reward from fostering and to continue being a foster carer (Whenan, Oxlad, \& Lushington, 2009). The management of challenging behaviour through specific strategies and parenting style has been the focus of training packages for foster carers. However, the efficacy of this training to ameliorate challenging behaviour and increase the capacity of foster carers to cope has been shown to have no significant effect in comparison to foster carers not in receipt of training (Macdonald \& Turner, 2005; Pithouse, Hill-Tout, \& Lowe, 2002).

The research literature demonstrates that the ability of a foster carer to maintain a secure, stable relationship with a foster child exhibiting challenging behaviour is likely to be dependent on a number of factors including the carer's emotional resilience, attachment style, personality and distress tolerance. Whilst there has been some empirical research looking at the resilience of children in foster care, little if any has addressed the emotional resilience of foster carers. The meta-analysis carried out by Oosterman et al. (2007) suggested that data regarding foster carer characteristics were inconclusive. Consequently a detailed qualitative study may act as a starting point for research into the role that the emotional resilience of foster carers plays in promoting placement stability.

\section{Method}

This study received full ethical approval from Northumbria University Department of Psychology Ethics Committee.

\subsection{Participants}

The study was carried out in the North East of England. Sixteen foster carers working for a Local Authority as contract carers were identified by the Fostering Service as having formed stable placements with children exhibiting challenging behaviours and were invited by letter to take part. Seven foster carers (one male; six female) replied and gave informed consent to attend a focus group and a one-to-one interview. All names are changed for inclusion in this report.

"Tom" (58 years) had been fostering for 13 years and had fostered "dozens" of children, many short-term, emergency placements; however a number were long-term placements of many years duration. Some of these children, now young adults, still maintained close contact and lived at home from time to time. Currently "Tom" was fostering two boys aged 11 and 16 years. He lived with his wife (second marriage) and had a son and three step-daughters. When he started fostering all the children were adults and only one lived at home. "Tom" came from a family with low socio-economic status; he had two brothers and two sisters and had left school at 15 years with no formal qualifications. He worked at evening and weekend jobs from 12 years and on leaving school had a variety of jobs before joining the Army. On leaving the Army he again had a variety of manual jobs before becoming a house builder.

"Anne" (58 years) had been fostering for six years and had had only one child (female) from the age of 10 years. She had never been married nor had children of her own; she did however have a partner who did not live with her. "Anne" had been brought up with a sister in the South of England. She described her childhood as "not very 
happy" and during her teenage years had a difficult relationship with her father. She left school at 14 years with no formal qualifications. Whilst working in a shop and as a short-hand typist she attended night school to get O' Levels and A' Levels. Subsequently she went to University and was awarded a degree in Psychology; she then completed a PhD. "Anne" had worked in the Probation Service and with the Youth Offending Team before becoming a foster carer.

"Brenda" (52 years) had been fostering for seven years and had fostered about 15 children including some for respite care. She was married and had two children, one from her previous marriage, and whilst both children had lived at home when she started fostering, at the time of interview, only one was still at home. Currently she was fostering three boys, one aged 16 years was in a long-term placement and had been with her for seven years, the two other boys (aged 8 and 3 years) were in short-term placements and had been with her six and five months respectively. "Brenda" had left school at 16 years with some CSE qualifications and had worked in a shop and then for a printing firm for 22 years before being made redundant and having her second child at the age of 40 years. She was brought up with a brother, and a sister was born when she was 17 years old. She described her childhood as "happy" and her father as "very strict".

"Carol" (50 years) had been married for thirty years and had two grown-up children. She started fostering six years ago as part of a Treatment Foster Care programme which involved extensive training and support. She fostered two children through the programme leaving to become a contract carer when she took on the second child in a long-term placement. At the time of the study she was fostering two boys, one in a long-term placement (three and a half years) and the other with a view to becoming a long-term placement. "Carol" had "quite a happy childhood" and was the second oldest of two sisters, with a younger brother. She had a turbulent relationship with her mother as a teenager and adored her father. She left school at 16 years with a few CSE qualifications, working first in a shop and then for the school meals service where she worked her way from washing pots to being a cook and an area manager; this included studying at night school.

"Diane" (46 years) had been married for 19 years and had two children still living at home. She had left school at 17 years with O' Levels and having started A' Levels. She worked first as a business travel consultant and then for a financial and card services company becoming an operations director. She began fostering five years ago when she was made redundant. She had fostered a total of nine children (excluding respite care) for between five months and four years. At the time of the study she had four foster children, two siblings in a long-term placement (four years) and two in short-term placements. "Diane" was an only child of an older mother; her father died when she was eighteen months old. She was largely looked after by her grandmother with whom she had an "awful relationship"; despite this "Diane" described her childhood as happy.

"Elaine" (55 years) had been fostering for 20 months during which time she had had one foster child (male, aged 6 years). She had been widowed three years previously and had a grown-up, married son and grandchild. "Elaine" was the second oldest of three sisters and described her childhood as "happy". She had been particularly close to her father and was perceived to be his "favourite" by her sisters. Discipline was meted out by her mother. "Elaine" left school at 16 years with some CSE and O' Level qualifications. She did a year at college before starting work in a Chemist shop. She left work to have her son and took up part-time work in a bakery when he was twelve.

"Fiona" (37 years) had been fostering for nine years, during which time she had fostered approximately 30 children (including respite care). At the time of the study she had one child (male) in a long-term placement (six years) and another child (male) in a short-term placement. "Fiona" described her childhood as "the best"; she had an older sister and had been particularly close to her father who for much of her childhood had suffered ill-health following an industrial accident. She left school at 16 years with GCSE qualifications and had a job where she worked her way up from sales assistant to manager. "Fiona" had been married for 17 years and left work when she had her first child (of two).

\subsection{Sources of Data}

The focus group took place before the interviews. The seven participants were seated in a circle with the researcher and a Clinical Psychologist, who was known to all the participants, in a quiet, private room in the University. A schedule of questions was used to guide the discussion which lasted for 91 minutes and was digitally recorded (Olympus digital voice recorder VN-5500PC; Olympus Imaging \& Audio Ltd. Essex, UK). Following the focus group, the interviews took place over five consecutive weeks, with a maximum of one interview per day. Interviews took place in a quiet, private room in the University and ranged from 67 to 130 minutes duration; and were digitally recorded. A schedule of questions was used to guide the conversation, with additional questions being added during the course of the interviews. Questions relating to six "events", known 
to have a detrimental effect on foster carer well-being (Wilson, Sinclair, \& Gibbs, 2000), were included in the interview schedule. All the interviews involved the foster carer and researcher, with the exception of the interview with "Diane" where a last minute cancellation of a contact visit meant that her 18 month old foster child was present.

Transcription of data: Within a few hours of the focus group or interview the audio file was downloaded onto a laptop computer (Vostro 1700 laptop, Dell Corporation Ltd, Berkshire, UK) and the audio file converted from WMA format to WAV format for use with open source audio software (Audacity, open source software; www.audacity.sourceforge.net). Verbatim transcripts were produced from the digital recordings and used to develop further questions for use in the one-to-one interviews and in the analysis. All recording and transcription was carried out by the same researcher.

Procedures for analysis: An inductive grounded theory approach was adopted (Glaser \& Strauss, 1967) following the method of Charmaz (2006). Each transcript was read several times and coded line by line. Once all transcripts had been subjected to this initial coding, a focused coding review was carried out resulting in a set of preliminary codes and categories. A number of further reviews were carried out and where necessary codes and categories were amended and re-defined until a final set of codes and categories was found to fit the data. The final codes and categories were found to be encapsulated by three overarching categories.

\section{Results and Discussion}

The aim of this study was to explore the role that the emotional resilience of foster carers plays in promoting placement stability. Placement stability (a positive outcome) is achieved when a Looked After Child (a child in the care of a Local Authority whether in a residential or foster home) had fewer than three placements in a year and, where that child had been in care for at least $2 \frac{1}{2}$ years, they had been in the same placement for two years ("National Indicators for Local Authorities and Local Authority Partnerships: Updated National Indicator Definitions," 2009). Conversely placement instability (a negative outcome) occurred when a Looked After Child had three or more placements in a year and, where that child had been in care for at least $2 \frac{1}{2}$ years, had placements lasting less than two years. In this study, with the exception of one foster carer who had been fostering for 20 months, all the foster carers had at least one foster child who had been with them for more than 2 years, and therefore had experienced positive placement outcomes (placement stability). Many of the children fostered by these carers exhibited challenging behaviours, most of which were externalising, biting, kicking, hitting, spitting, for example. A few children were on the autistic spectrum and were sometimes withdrawn (internalising behaviours).

Figure 1 shows the category tree derived from the transcript data. The figures in parentheses indicate the prevalence with which each code appeared amongst the foster carers (maximum $=7$ ); only those codes identified for a least four foster carers were included. The data codes shown on the left hand side of the figure feed into first and second higher-order latent constructs to the right. Three second higher-order latent constructs, emotional resilience, interpersonal characteristics and external factors appeared to act either to promote placement stability or to increase the likelihood of placement breakdown. The figure also includes "foster child characteristics", which whilst not investigated in this study, have been shown to be important in influencing parenting and determining placement outcomes (Clark, Kochanska, \& Ready, 2000; Duelling \& Johnson, 1990; Sinclair \& Wilson, 2003).

The emotional resilience of these foster carers made a contribution to the placement outcomes. Emotional resilience was defined by three first higher-order latent constructs, managing emotions, personal attributes and personality traits. The ability of these foster carers to manage their emotions was a key facet of their emotional resilience and could be related to the construct of distress tolerance which is a measure of an individual's capacity to tolerate, appraise, absorb and regulate negative emotions (Simons \& Gaher, 2005).

They experienced episodes of emotional distress particularly related to difficult situations that occurred during both short- and long-term placements. In some cases the foster carer found it impossible to continue and had to ask to have the child removed, one such was "Carol" who had had a child attempt suicide:

"I was breaking my heart on the phone so they knew they had to do it that day d'yer know what? I just said, I don't want him back, just take him, but, so they did..." (Carol)

Despite having to end the placement, "Carol" demonstrated her emotional resilience by going on to foster other children with challenging behaviours.

The ability to manage distressing emotions was helped by the hardiness of these foster carers who in the main did not report becoming overwhelmed by emotional distress or who were able to bounce back following a 
distressing episode. This hardiness was characterised by an ability to overlook challenging behaviour:

"...and no matter what she did we kept her right 'til the end'..." (Fiona)

And to manage the emotional distress associated with a foster child leaving, a regular occurrence in short-term placements,

"I have had other children of a similar age where I haven't felt as bad, I've still been upset, but I haven't felt as completely devastated erm, but with her that was probably, that's probably the worst, worst moment that we've had really" (Diane).

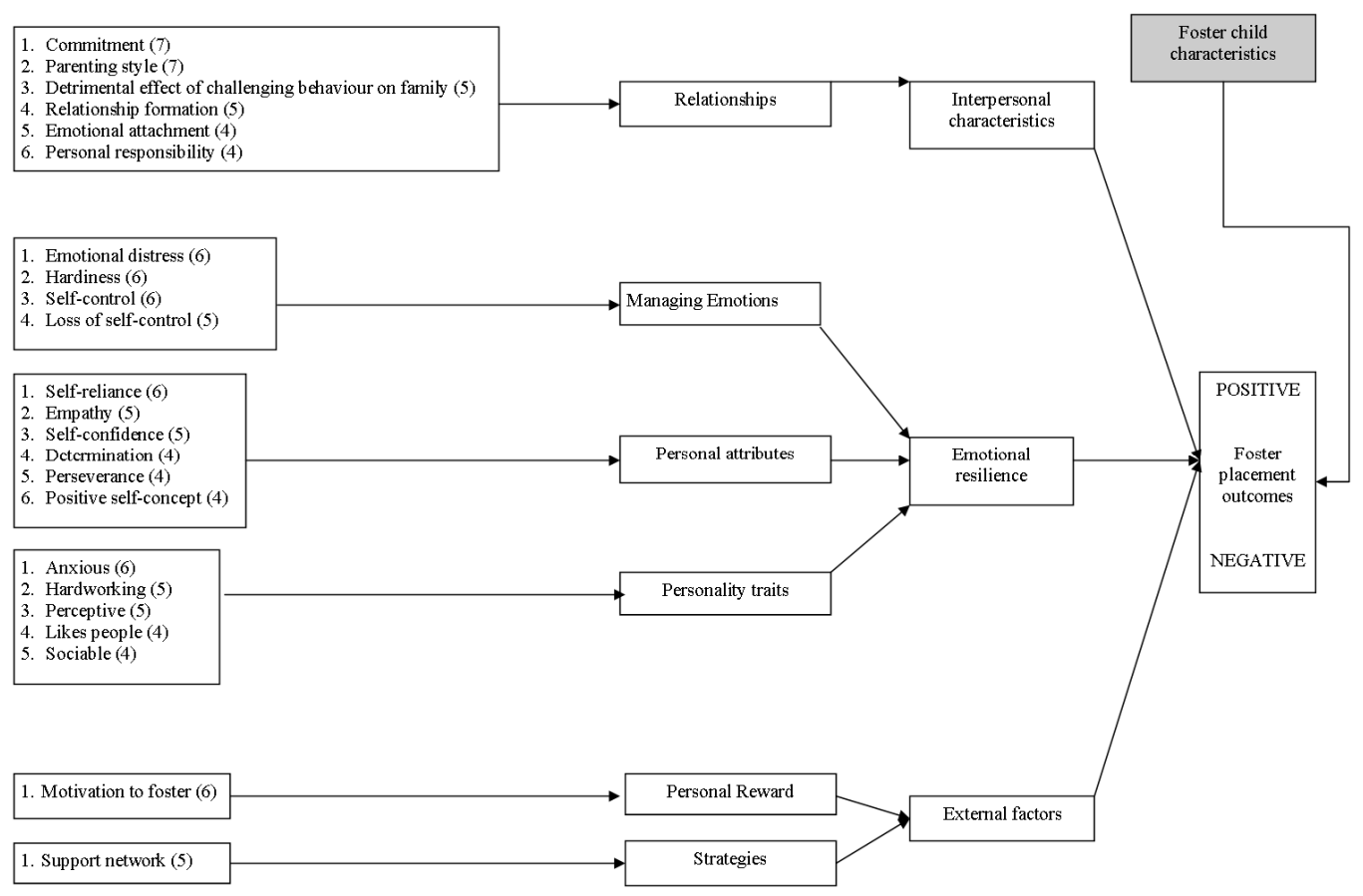

Figure 1. Category tree developed from the analysis of the data

The concept of hardiness has been characterised as an individual who has an internal locus of control, is immersed and committed to the activities in their life, and who has a positive view of change. These characteristics have been shown to have a protective function in high stress situations (Kobasa, 1979). It is possible therefore that their hardiness helped to protect these foster carers from the negative effects of their foster children's challenging behaviour. Furthermore, hardiness has been shown to be exhibited by resilient-functioning adults (Bonanno, 2004).

The capacity to overlook challenging behaviour may be related to the ability of these foster carers to alter their attentional focus and attribute positive meaning to challenging behaviour (Gross, 1998), as exemplified by "Carol":

“...he's a canny bairn really you know, it's not his fault is it?" (Carol)

The ability to manage emotions was also related to emotional self-control; a characteristic evident in most of these foster carers. A common occurrence was remaining calm in the face of challenging behaviour or in the case of "Brenda", not retaliating in the face of a malicious allegation made by a birth parent:

"I couldn't believe it, I honestly couldn't believe it, and then I was mad, you can imagine, I was mad, but as, I mean I still had to go and see mam and just act as if nothing had happ..., because I knew I hadn't done anything..."(Brenda)

However, there were times when these foster carers experienced a loss of self-control with consequent displays of anger, frustration and tears. "Tom" found that his temper got the better of him from time to time:

"I lost it this day mind I must admit, illegal what I done..." (Tom) 
Despite the occasional lapse of self-control these foster carers were able to bounce back and continue with the foster placement, again demonstrating their emotional resilience in the face of adverse circumstances. A possible model to explain this finding is that of ego-resiliency and ego-control where self-control (and loss of self-control) are viewed as the control of impulses. According to the construct ego-control, these foster carers would be positioned along a continuum from ego-undercontrol to ego-overcontrol. Given their capacity to control their impulses in the face of challenging behaviour, it can be postulated that they are moderately ego-overcontrolled (Kremen \& Block, 1998; Letzring et al., 2005).

Emotional resilience was also defined by these foster carers' personal attributes. Unless in the Treatment Foster Care programme, foster carers work largely on their own; they described fostering as "lonely" and "isolating", and felt supported or unsupported by their link (social) worker in equal number. A very common characteristic was that of self-reliance; they saw themselves as independent and unwilling to depend on anyone other than their spouse or partner:

"I don't know who I depend on apart from E... ... I hate asking people to do anything." (Carol)

This was an important characteristic as being the main carer meant that managing challenging behaviour largely fell to them.

In advance of any placement these foster carers were provided with information about the child and the circumstances of their being taken into care. This helped them to understand and empathise with the child, so that they could respond appropriately to challenging behaviour. "Tom" drew on previous life experience to help him understand the children in his care:

"I can, most of these kids I can relate te, because, most of the kids, I been there..." (Tom)

They demonstrated their self-confidence in the decisions that they made regarding their foster child, and although legally, permission from the Fostering Service had to be sought in regard to many of the decisions they made, these foster carers felt they were best placed to make those decisions. "Fiona" was confident that given her experience:

“...the fostering trust me judgement on things...” (Fiona)

Additionally, they were determined, prepared to fight for what they believed to be best for their foster child, even if that meant taking on institutions and professionals:

"I've fought tooth and nail to get every single thing for him, I've fought education, social workers, I've had him, all sorts, he is what he is today and I know that is because of my and my husband's really hard work getting the right therapy for him..." (Fiona)

The ability to be able to persevere in the face of on-going difficulties was typical of most of these foster carers and is characteristic of emotionally resilient people:

“...we made some noises to social services who took no notice at first and then we got the children's guardian involved again..." (Diane)

"Diane's" pragmatic response was an example of a cognitive coping strategy. These are known to be used by foster carers to appraise situations in a positive way, thus preventing undue negativity and promoting perseverance (Lazarus, 1991).

For a number of these foster carers, a positive self-concept was evident. They felt that they were able to get on with other people, were good at fostering and had attributes such as being caring and having a good sense of humour. Given that the foster carers work on their own it was important that they held a positive view of themselves and it contributed to their emotional resilience. "Brenda" recognised that she was good at connecting with a variety of people:

"I find it easy to talk to people, erm, so, I think that's, you know, it always breaks the ice doesn't it? And just find something in common type of thing and find something that they're interested in..." (Brenda)

It is possible that under stressful situations these foster carers were able to modify the structural component of their self-concept such that the stress had less of an adverse effect on them. This has been shown to be the case in depressed patients (Showers, Abramson, \& Hogan, 1998) and may help to explain why these foster carers were better able to cope with challenging behaviours than other foster carers.

A third facet of emotional resilience was the personality traits exhibited by these foster carers which appeared to map onto the Five Factor model of personality (Costa \& McCrae, 1992), namely, Openness, Conscientiousness, Extraversion, Agreeableness and Neuroticism. Anxiety is a trait associated with Neuroticism which has been 
shown to be associated with inflexible coping strategies (Lee-Baggley, Preece, \& DeLongis, 2005). Almost all of these foster carers expressed feelings of anxiety related to their foster child(ren) and at times wondered if they had the resources to cope. "Elaine" described her fear in response to a situation where her foster child, because he had no more Christmas presents to open, held his breath and turned blue:

"Frightened, very frightened because you, at first you think you know, how can I cope?" (Elaine)

It was striking, however, that these foster carers reported very few situations where placements were prematurely ended. It is therefore possible that these foster carers were able to find positive meaning within difficult situations and used these insights to cope more effectively next time; the "broaden and build" model (Tugade \& Fredrickson, 2004). If this is the case then it might be expected that foster carers who had been fostering longer (for example "Tom") would cope better than foster carers who had only recently started (for example "Elaine").

These foster carers were hard-working; something that was apparent in their early lives, where through their own efforts they had achieved a great deal. "Anne", having left school at 14 years with no formal qualifications had worked her way through night school and full-time education to become a probation officer:

"And then I did O' Levels at evening class, and then I did six A' Levels at evening class, and then I did a degree at D..., and then I did a counselling course at D..., then I did social work, no, then I did a PhD, and then I did the social work to do er, probation..." (Anne)

It is possible that these foster carers employ relationship-focused coping strategies to enable them to achieve positive outcomes with their challenging foster children. In a study of parents and step-children it was found that parents high for Conscientiousness (of which hard-working is a trait) used relationship-focused coping strategies more than those low for the dimension (Lee-Baggley et al., 2005).

Another personality trait present in these foster carers that contributed to their emotional resilience was perception; they were able to understand and adapt to the needs of their foster child:

"I think that's what a lot of these children is don't expect too much from them too quickly and just little small things at a time, don't expect them to come in and be like your children cos they cannot, they can 't function like that, so it's just little bits at a time..." (Fiona)

Perception is a trait of Openness and has also been shown to be related to ego-resiliency (Klohnen, 1996). Parents high for Openness have been shown less likely to distance themselves from distressing emotions than those parents low for this dimension (Lee-Baggley et al., 2005). Similarly, the foster carers taking part in this study did not appear to distance themselves from their foster children, often staying with them despite distressing or challenging behaviour:

"I would sit and talk to him and he would be going crazy on us you know and you just have to keep calm, try and tell them that you understand..." (Fiona)

Perhaps not unsurprisingly these foster carers liked people, and children in particular:

"I quite like having children around and I think I'm quite good at it, erm quite good at looking after children I think because I had such a busy, busy job and a, a really stressful career erm, I had quite a lot of capacity to do lots of things erm, I was used to being busy all of the time you know..." (Diane)

They were also sociable:

"I loved the working with people... and the trying to keep, get the people involved..." (Anne)

Both these traits, "liked people" and "sociable" are indicative of Extraversion, a domain that has been shown to enable parents of step-children to build positive relationships and to cope flexibly with difficult behaviour (Lee-Baggley et al., 2005).

Interestingly, resilience has been shown to have a strong inverse relationship with Neuroticism and strong positive relationship with Extraversion and Conscientiousness (Campbell-Sills, Cohan, \& Stein, 2006). However when task-orientated and emotion-orientated coping styles were included in the regression model, Conscientiousness was no longer a significant predictor because a task-orientated coping style mediated the relationship between resilience and Conscientiousness.

A number of interpersonal characteristics of these foster carers helped to determine foster placement outcomes. These interpersonal characteristics were defined as those that these foster carers employed in the formation and maintenance of relationships with foster children, birth parents and professionals involved in the care of the foster child. The formation of a relationship with a child who exhibited challenging behaviours was not easy and did not work in every instance, but the foster carers agreed that an important aspect of relationship formation 
was treating the foster child and their own children in the same way:

"You've got to treat them the same as your own..." (Tom)

It is possible that this inclusivity aids the formation of a positive carer-child relationship through the raising of the child's self-esteem (Luke \& Coyne, 2008). A positive relationship increases the likelihood of a more stable placement. It is interesting to note that these foster carers observed that many other foster carers did not have such an inclusive approach, particularly where holidays were concerned, with foster children being put into respite care rather than being taken on family holidays.

Most of the foster carers recognised that their parenting style with their foster child(ren) was different to that they had used with their own children. Parenting style was influenced by their training as foster carers; this was particularly the case for "Carol" who had been part of the Treatment Foster Care programme which used a strict "sanctions and rewards" approach. Given the chaotic life that many of the foster children had experienced before coming into care, the foster carers recognised the importance of boundaries and routines in helping the foster child settle into their new family life:

“...if you can get at the routines and boundaries established, it's not going to work straight away, but they do respond well to them and their behaviour, I think, for the most part can improve quite quickly..." (Diane)

A particular issue for foster carers was control; in situations where the foster child had gained the upper hand, the sanctions/rewards approach offered a way of the foster carer regaining control which may be why it is an effective coping strategy (Folkman \& Moskowitz, 2004).

Not all of the parenting styles were the same; "Tom" had an approach that worked with his older, "street-wise" foster children:

\section{“...they weren't bad-uns they just wanted a good seeing to, good talking to..." (Tom)}

The authenticity of the parenting style used by the foster carer appeared to be important. "Elaine" had recently been on a "Team Teach" course which encouraged the foster carer to ignore challenging behaviour and walk away. She had found that it worked in calming down her foster child's angry outbursts, but was "completely different" to how she would have handled this behaviour before.

Most of the foster carers had had multiple short-term placements, some of which they had converted to long-term placements. These appeared to be with foster children that they formed a strong emotional attachment to:

"I could never give R... up to do that now, I mean I've done what they say you shouldn't do and I've getting too attached to him." (Elaine)

The adult attachment style of a parent has been shown to be strongly predictive of the attachment of a child, with children of autonomous parents being very likely to be securely attached to that parent (Van Ijzendoorn, 1995). However, it is not possible to know from the data collected in this study what the attachment styles of these foster carers are. Additionally, given that attachment relationships between parent and child are normally formed during the first year of life (Bowlby, 1984), and subsequent attachment to foster carers is known to be difficult (Hughes, 2006), nothing can be said about the attachment of the foster children to their foster carer and how that might affect placement outcomes.

Whilst these foster carers formed enduring relationships with some foster children, this did not happen in every case. A number of the foster carers commented on the significance of the age of the child when they came into care, with the younger they are, particularly under three years of age, the more likely they are to form a stable relationship. Dozier (2005) found that babies under one year of age settled more quickly in a placement than babies over one year. This probably reflects the length of time a child has been subject to abuse, neglect or trauma prior to coming into care and acknowledges the fact that relationship formation is a two-way process:

“...they're building the stable relationship with you as well as that the other way round...” (Diane)

It was clear that each of the foster carers was hugely committed to the foster child(ren) in long-term placement. The passion with which the foster carers expressed their commitment to these children was palpable:

"I would never, ever, ever, ever let go to A..., I would walk over hot coals to keep him, I really would..." (Fiona)

The foster children cared for by these foster carers presented with challenging behaviours: harming themselves, harming others (particularly the main foster carer) and damaging property (their own and the foster family's). The foster carers described the behaviour as "horrific", "horrendous" and "not normal" and sometimes found the behaviours outside of their experience; particularly true for those foster carers who had only been fostering for a 
short time. Almost the only reason that the foster carers gave for ending a placement was the effect of the challenging behaviour on the family. Perhaps because of the commitment that these foster carers felt towards these foster children, ending a placement was associated with feelings of guilt:

"... you can't go on with that placement when these other two children are so upset and so, then you have to move them on, but you do feel awful, but you've got to think of the children that you've already got. You've got to." (Brenda)

Despite the challenging behaviour the foster carers felt personally responsible for the success or failure of the placement and saw having to "give up" as a personal failure:

"I think the commitment's a big thing ... it would be the easiest thing in the world to just say agh, I just can't do this anymore, but, trying to think of the impact of giving up on her and her sibling now and the damage that would do, you, you just can 't, it's, it's just incomprehensible." (Diane)

The attachment and commitment to these children and the sense of personal responsibility experienced by these carers appeared to enable them to endure the challenging behaviours beyond that which other foster carers were willing or able to go.

There were two external factors that appeared to affect placement outcomes for these foster carers. The foster carers gained personal reward through fostering and were motivated by their desire to give disadvantaged children an opportunity for a better life and for some by their strong maternal instincts that meant that they simply adored children and wanted to have them in their house:

"I thought give a kid a life sort of thing, give him a chance..." (Tom)

This finding is supported by a previous study (Dando \& Minty, 1987) that demonstrated a relationship between motivation to foster and being rated as an excellent foster carer, with placement stability.

The single most important strategy that was employed by these foster carers was a support network which covered family, friends and professionals and which was used as a safety valve for their emotions. The confidentiality that surrounds a foster child makes it difficult for the foster carers to be able to talk about what has happened and the effect that the behaviour of the foster child has on them, although they recognise the need to off-load for their own well-being:

"Me son ... Yeah, he phones, he phones me every night at nine o'clock to see if I need bit moan." (Elaine)

This strategy is an example of both social coping and emotion-focused coping (Folkman \& Moskowitz, 2004). Foster carers have previously highlighted support networks as a key requirement for successful placements (Brown, 2008). Support networks have also been shown to alleviate foster carer stress, a predictor for placement breakdown (Farmer et al., 2005).

Multiple codings of the transcripts highlighted the central role that emotional resilience played in determining placement outcomes. It also showed that the higher-order latent constructs did not act independently to affect placement outcomes, but instead were highly interrelated. Additionally, placement outcomes acted in a way to feedback on the latent constructs and affect how these were expressed. The strongest interrelationships were between emotional resilience and interpersonal characteristics, which was the result of strong interrelationships between managing emotions, personal attributes and personality traits with relationships.

A consistent characteristic of the children cared for by these foster carers was their challenging behaviours which could lead to negative placement outcomes such as detrimental effects on other family members and ultimately the ending of the placement. The detrimental effect of challenging behaviour on the family clearly impacted on the emotional distress experienced by these foster carers:

“...it very much affected my family, we had to go on holiday, the kids were completely damaged by it and I'm now as a mother feel horrendous but I could never known it was going to happen..." (Fiona)

The negative impact of a foster child on the family was the only consistent reason these foster carers gave for ending a placement; something mirrored in other studies (Brown \& Bednar, 2006; Jones \& Morrissette, 1999; Wilson et al., 2000). It is possible that the increased likelihood of placement breakdown is caused by impairment of parenting skills which are adversely affected by foster carer stress (Farmer et al., 2005). The emotional distress experienced when a placement ended, even if this was a planned event, was too much for some of these foster carers. They gave this as a reason for only taking on foster children with a view to them being long-term:

"I couldn't do that, in me life I couldn't every four or five weeks say, cheerio, move on." (Carol) 
These foster carers described the unremitting challenging behaviour of their foster child as exhausting and "not pleasant" to watch and at times it made them feel as though they could not take any more. It influenced their parenting style, through which they sought to limit their own emotional distress:

"And, but they keep, and then of course one says the other one, then that one, then that one, and ah, it goes on and on and on and on and I just think, ee, I'm sick of this, I'm really sick of this, and I go in and say, right, that's it, I've had enough, I'm up to here, I'm fed up with all o'yers, you in your room, you in your room and you be quiet. And it just gets, get us so, you know, because they just go on, and it's constant, unbelievable, and it, it wears you down." (Brenda)

This ability to manage challenging behaviour has been shown to increase foster carers' sense of well-being and satisfaction with fostering, and thereby make placement stability more likely (Whenan et al., 2009). Whilst these foster carers did report occasional instances of having to end a placement because they could no longer cope, it was a rare occurrence, mostly they remained committed to the child and the placement. For "Anne" who was very self-reliant, the commitment to her foster child was a surprise to her:

"I'm commitment phobic really, I've never, ever made a commitment to anybody, so the fact that taking a child was actually sort of the first time that I'd ever said to anybody that I would, erm, you know, keep them forever really." (Anne)

Parenting style varied between these foster carers and appeared to be influenced by their emotional resilience. "Fiona" was perceptive, and used this to help vary her parenting style to match the needs of the foster child:

“...in that first six month they can be pretty challenging and you've just got to try and find out who they are as a person really erm, see what works and what doesn't, it's trial and error..." (Fiona)

"Elaine" appeared to draw on hardiness to ensure that she was consistent in her approach:

“...as I say he knows I mean it, I do, that's one thing, you know I never go back on what I say.” (Elaine)

It was clear that the children in long-term placements were children with whom the foster carers had formed a strong emotional attachment. Associated with this, for some of these foster carers, was anxiety that the Fostering Service might decide to end the placement and that they would "lose" the child:

"I would be really hurt if they decided that for whatever reason that he shouldn't live with me anymore..." (Elaine)

These foster carers took personal responsibility for the placement outcomes. "Fiona" seemed to like to take responsibility for everyone:

"I just like to make things happy for people, I've always been like that, I just like to make sure everybody's alright." (Fiona)

Again, "Elaine's" hardiness was evident in her feelings of responsibility for her foster child even if the placement were to end:

“...but at the end of the day I don't think I can give up on him, honestly, I, I would feel too guilty, to think you know, what erm, if anything went wrong after I gave him up I'd blame meself..." (Elaine)

These foster carers understood that relationship formation took time and employed their emotional resilience to cope with whatever the foster child threw at them. They appeared to keep the end goal in mind, a comfortable relationship with the foster child and a positive placement outcome:

“...it's just about the fact that you're prepared to put up with all that bad behaviour, and all that stuff, and think, for long enough that the relation.., that's why I think I asked about the how or the why because if somebody is prepared to stick with it then I think the relationship will happen." (Anne)

\section{Conclusions}

This study has identified an extensive range of characteristics and factors that were employed by these foster carers to promote placement stability. The construct of ego-resiliency appears to be the most useful in explaining the findings. These foster carers were subject to a daily diet of challenging behaviours and yet, for the most part remained buoyant and optimistic about continuing with the placement. Through modulation of ego-control, ego-resiliency (emotional resilience) enables the foster carer to be flexible in their response to a range of stressful situations. Their adaptability clearly involved the management of their emotions which is suggestive of their being moderately ego-overcontrolled.

It is not possible to know from the data whether the foster carers in the current study had experienced significant 
childhood adversity that would have led to the development of resilience (Luthar et al., 2000; Rutter, 1985). Whilst the foster carers variously reported coming from a low socio-economic background, difficult relationships with a parent or grandparent, and illness or death of a parent, similar episodes occur in the lives of many people. However, Masten (2001) proposes that given that the majority of people exhibit resilience it must be part of normal human development rather than being dependent on the presence or absence of childhood adversity as much of the literature suggests.

It was always the intention that this qualitative study would form the starting point for further investigation. In the proposed model, the relationships between emotional resilience, interpersonal characteristics and external factors appear important. Which contribute most in determining placement outcomes is difficult to identify. To answer this, a number of questionnaires exist that could form the basis of such a quantitative study to develop a quantitative model in a wider population of foster carers. In summary, the emotional resilience of foster carers has been found to play a role in promoting placement stability, and this is worthy of wider investigation.

\section{References}

Ainsworth, M. S. (1979). Infant-mother attachment. American psychologist, 34(10), 932. http://dx.doi.org/10.1037/0003-066X.34.10.932

Block, J., \& Kremen, A. M. (1996). IQ and ego-resiliency: Conceptual and empirical connections and $\begin{array}{llllll}\text { separateness. Journal of personality and social psychology, } 70(2), & 349 .\end{array}$ http://dx.doi.org/10.1037/0022-3514.70.2.349

Bonanno, G. A. (2004). Loss, trauma, and human resilience: Have we underestimated the human capacity to thrive after extremely aversive events? American psychologist, $59(1), 20$. http://dx.doi.org/10.1037/0003-066X.59.1.20

Bowlby, J. (1984). Attachment and loss: Volume 1. Attachment (Revised ed.). London: Pimlico.

Brown, J. D. (2008). Foster parents' perceptions of factors needed for successful foster placements. Journal of child and family studies, 17(4), 538-554. http://dx.doi.org/10.1007/s10826-007-9172-z

Brown, J. D., \& Bednar, L. M. (2006). Foster parent perceptions of placement breakdown. Children and Youth Services Review, 28(12), 1497-1511. http://dx.doi.org/10.1016/j.childyouth.2006.03.004

Campbell-Sills, L., Cohan, S. L., \& Stein, M. B. (2006). Relationship of resilience to personality, coping, and psychiatric symptoms in young adults. Behaviour Research and Therapy, 44(4), 585-599. http://dx.doi.org/10.1016/j.brat.2005.05.001

Charmaz, K. (2006). Constructing grounded theory: A practical guide through qualitative analysis. London: Sage.

Children looked after in England (including adoption and care leavers) year ending 31 March 2010. (2010) Retrieved from http://www.dcsf.gov.uk/rsgateway/DB/SFR/s000960/index.shtml

Clark, L. A., Kochanska, G., \& Ready, R. (2000). Mothers' personality and its interaction with child temperament as predictors of parenting behavior. Journal of personality and social psychology, 79(2), 274. http://dx.doi.org/10.1037/0022-3514.79.2.274

Costa, P. T., \& McCrae, R. R. (1992). Normal personality assessment in clinical practice: The NEO Personality Inventory. Psychological assessment, 4(1), 5. http://dx.doi.org/10.1037/1040-3590.4.1.5

Cyr, C., Euser, E. M., Bakermans-Kranenburg, M. J., \& Van Ijzendoorn, M. H. (2010). Attachment security and disorganization in maltreating and high-risk families: A series of meta-analyses. Development and Psychopathology, 22(1), 87. http://dx.doi.org/10.1017/S0954579409990289

Dando, I., \& Minty, B. (1987). What makes good foster parents? British Journal of Social Work, 17(4), 383-399.

Dozier, M. (2005). Challenges of foster care. Attachment \& human development, 7(1), 27-30. http://dx.doi.org/10.1080/14616730500039747

Duelling, J. L., \& Johnson, J. H. (1990). Predicting success in foster placement: The Contribution of Parent-Child Temperament Characteristics. American Journal of Orthopsychiatry, 60(4), 585-593. http://dx.doi.org/10.1037/h0079210

Farmer, E., Lipscombe, J., \& Moyers, S. (2005). Foster carer strain and its impact on parenting and placement outcomes for adolescents. British Journal of Social Work, 35(2), 237-253. http://dx.doi.org/10.1093/bjsw/bch181 
Flores, E., Cicchetti, D., \& Rogosch, F. A. (2005). Predictors of resilience in maltreated and nonmaltreated Latino children. Developmental Psychology, 41(2), 338. http://dx.doi.org/10.1037/0012-1649.41.2.338

Folkman, S., \& Moskowitz, J. T. (2004). Coping: Pitfalls and promise. Annu. Rev. Psychol, 55, 745-774. http://dx.doi.org/10.1146/annurev.psych.55.090902.141456

Funder, D. C., Block, J. H., \& Block, J. (1983). Delay of gratification: Some longitudinal personality correlates. Journal of personality and social psychology, 44(6), 1198. http://dx.doi.org/10.1037/0022-3514.44.6.1198

Glaser, B. G., \& Strauss, A. L. (1967). The discovery of grounded theory. New York: Aldine.

Gross, J. J. (1998). The emerging field of emotion regulation: An integrative review. Review of General Psychology, 2(3), 271. http://dx.doi.org/10.1037/1089-2680.2.3.271

Hughes, D. A. (2006). Building the bonds of attachment: Awakening love in deeply troubled children (2nd ed.). Maryland, USA: Jason Aronson.

Jones, G., \& Morrissette, P. J. (1999). Foster Parent Stress. Canadian Journal of Counselling, 33(1), 13-27.

Klohnen, E. C. (1996). Conceptual analysis and measurement of the construct of ego-resiliency. Journal of personality and social psychology, 70(5), 1067. http://dx.doi.org/10.1037/0022-3514.70.5.1067

Kobasa, S. C. (1979). Stressful life events, personality, and health: An inquiry into hardiness. Journal of Personality and Social Psychology, 37(1), 1. http://dx.doi.org/10.1037/0022-3514.37.1.1

Kremen, A. M., \& Block, J. (1998). The roots of ego-control in young adulthood: Links with parenting in early childhood. Journal of personality and social psychology, 75(4), 1062. http://dx.doi.org/10.1037/0022-3514.75.4.1062

Lazarus, R. S. (1991). Cognition and motivation in emotion. American psychologist, 46(4), 352. http://dx.doi.org/10.1037/0003-066X.46.4.352

Leathers, S. J. (2002). Foster children's behavioral disturbance and detachment from caregivers and community institutions. $\quad$ Children and $\quad$ 239-268. http://dx.doi.org/10.1016/S0190-7409(02)00175-5

Lee-Baggley, D., Preece, M., \& DeLongis, A. (2005). Coping with interpersonal stress: Role of Big Five traits. Journal of Personality, 73(5), 1141-1180. http://dx.doi.org/10.1111/j.1467-6494.2005.00345.x

Letzring, T. D., Block, J., \& Funder, D. C. (2005). Ego-control and ego-resiliency: Generalization of self-report scales based on personality descriptions from acquaintances, clinicians, and the self. Journal of Research in Personality, 39(4), 395-422. http://dx.doi.org/10.1016/j.jrp.2004.06.003

Luke, N., \& Coyne, S. M. (2008). Fostering self-esteem: exploring adult recollections on the influence of foster parents. Child \& Family Social Work, 13(4), 402-410. http://dx.doi.org/10.1111/j.1365-2206.2008.00565.x

Luthar, S. S., Cicchetti, D., \& Becker, B. (2000). The construct of resilience: A critical evaluation and guidelines for future work. Child development, 71(3), 543-562. http://dx.doi.org/10.1111/1467-8624.00164

Macdonald, G., \& Turner, W. (2005). An experiment in helping foster-carers manage challenging behaviour. British Journal of Social Work, 35(8), 1265-1282. http://dx.doi.org/10.1093/bjsw/bch204

Masten, A. S. (2001). Ordinary magic: Resilience processes in development. American psychologist, 56(3), 227. http://dx.doi.org/10.1037/0003-066X.56.3.227

Meltzer, H., Gatward, R., Corbin, T., Goodman, R., \& Ford, T. (2003). The mental health of young people looked after by local authorities in England. London: TSO.

Minnis, H., \& Del Priori, C. (2001). Mental health services for looked after children Implications from two studies. Adoption \& Fostering Journal, 25(4), 27-38.

Minnis, H., \& Devine, C. (2001). The effect of foster carer training on the emotional and behavioural functioning of looked after children. Adoption \& Fostering Journal, 25(1), 44-54.

National Indicators for Local Authorities and Local Authority Partnerships: Updated National Indicator Definitions. (2009) Retrieved from http://www.communities.gov.uk/publications/localgovernment/updatednidefinitions (Feb 23, 2011)

Newton, R. R., Litrownik, A. J., \& Landsverk, J. A. (2000). Children and youth in foster care: Disentangling the relationship between problem behaviors and number of placements. Child abuse \& neglect, 24(10), 1363-1374. http://dx.doi.org/10.1016/S0145-2134(00)00189-7 
Oosterman, M., Schuengel, C., Slot, N. W., Bullens, R. A. R., \& Doreleijers, T. A. H. (2007). Disruptions in foster care: A review and meta-analysis. Children and Youth Services Review, 29, 53-76. http://dx.doi.org/10.1016/j.childyouth.2006.07.003

Palmer, S. E. (1996). Placement stability and inclusive practice in foster care: An empirical study. Children and Youth Services Review, 18(7), 589-601. http://dx.doi.org/10.1016/0190-7409(96)00025-4

Pithouse, A., Hill-Tout, J., \& Lowe, K. (2002). Training foster carers in challenging behaviour: a case study in $\begin{array}{lllll}\text { disappointment? Child \& Family Social Work, } & \text { 7(3), 214. }\end{array}$ http://dx.doi.org/10.1046/j.1365-2206.2002.00249.x

Redding, R. E., Fried, C., \& Britner, P. A. (2000). Predictors of placement outcomes in treatment foster care: Implications for foster parent selection and service delivery. Journal of child and family studies, 9(4), 425-447. http://dx.doi.org/10.1023/A:1009418809133

Rubin, D. M., O'Reilly, A. L. R., Luan, X., \& Localio, A. R. (2007). The impact of placement stability on behavioral well-being for children in foster care. Pediatrics, 119(2), 336-344. http://dx.doi.org/10.1542/peds.2006-1995

Rutter, M. (1985). Resilience in the face of adversity: Protective factors and resistance to psychiatric disorder. British journal of psychiatry, 147, 598-611. http://dx.doi.org/10.1192/bjp.147.6.598

Rutter, M. (2006). Implications of resilience concepts for scientific understanding. Annals of the New York Academy of Sciences, 1094(1), 1-12. http://dx.doi.org/10.1196/annals.1376.002

Schofield, G., \& Beek, M. (2005a). Providing a secure base: Parenting children in long-term foster family care. Attachment \& human development, 7(1), 3-26. http:dx.doi.org/1080/14616730500049019

Schofield, G., \& Beek, M. (2005b). Risk and resilience in long-term foster-care. British Journal of Social Work, 35(8), 1283-1301. http://dx.doi.org/10.1093/bjsw/bch213

Showers, C. J., Abramson, L. Y., \& Hogan, M. E. (1998). The dynamic self: How the content and structure of the self-concept change with mood. Journal of Personality and Social Psychology, 75(2), 478. http://dx.doi.org/10.1037/0022-3514.75.2.478

Simons, J. S., \& Gaher, R. M. (2005). The Distress Tolerance Scale: Development and validation of a self-report measure. Motivation and Emotion, 29(2), 83-102. http://dx.doi.org/10.1007/s11031-005-7955-3

Sinclair, I., \& Wilson, K. (2003). Matches and mismatches: The contribution of carers and children to the success of foster placements. British Journal of Social Work, 33(7), 871-884. http://dx.doi.org/10.1093/bjsw/33.7.871

Tugade, M. M., \& Fredrickson, B. L. (2004). Resilient individuals use positive emotions to bounce back from negative emotional experiences. Journal of personality and social psychology, 86(2), 320. http://dx.doi.org/10.1037/0022-3514.86.2.320

Van Ijzendoorn, M. (1995). Adult attachment representations, parental responsiveness, and infant attachment: a meta-analysis on the predictive validity of the Adult Attachment Interview. Psychological bulletin, 117(3), 387. http://dx.doi.org/10.1037/0033-2909.117.3.387

Ward, H. (2009). Patterns of instability: Moves within the care system, their reasons, contexts and consequences. Children and Youth Services Review, 31(10), 1113-1118. http://dx.doi.org/10.1016/j.childyouth.2009.07.009

Webster, D., Barth, R. P., \& Needell, B. (2000). Placement stability for children in out-of-home care: a longitudinal analysis. Child Welfare, 79(5), 614-632.

Werner, E. E. (1993). Risk, resilience, and recovery: Perspectives from the Kauai Longitudinal Study. Development and Psychopathology, 5, 503-503. http://dx.doi.org/10.1017/S095457940000612X

Whenan, R., Oxlad, M., \& Lushington, K. (2009). Factors associated with foster carer well-being, satisfaction and intention to continue providing out-of-home care. Children and Youth Services Review, 31(7), 752-760. http://dx.doi.org/10.1016/j.childyouth.2009.02.001

Wilson, K., Sinclair, I., \& Gibbs, I. (2000). The trouble with foster care: the impact of stressful"events" on foster carers. British Journal of Social Work, 30(2), 193-209. http://dx.doi.org/10.1093/bjsw/30.2.193 